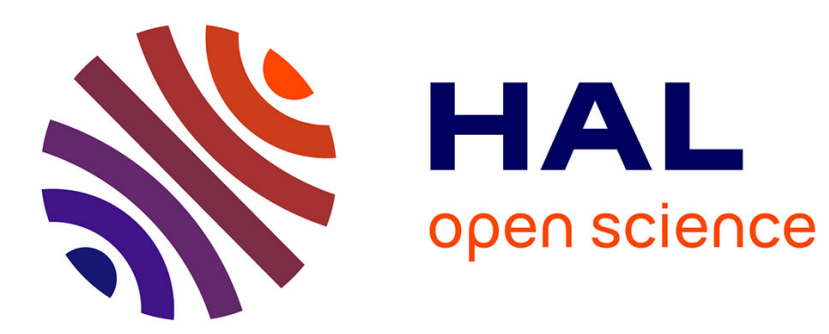

\title{
Determination of Plastic Properties of Polycrystalline Metallic Materials by Nanoindentation - Experiments and Finite Element Simulations
}

\author{
Bjoern Backes, Karsten Durst, Mathias Goeken
}

\section{- To cite this version:}

Bjoern Backes, Karsten Durst, Mathias Goeken. Determination of Plastic Properties of Polycrystalline Metallic Materials by Nanoindentation - Experiments and Finite Element Simulations. Philosophical Magazine, 2006, 86 (33-35), pp.5541-5551. 10.1080/14786430600735468 . hal-00513702

\author{
HAL Id: hal-00513702 \\ https://hal.science/hal-00513702
}

Submitted on 1 Sep 2010

HAL is a multi-disciplinary open access archive for the deposit and dissemination of scientific research documents, whether they are published or not. The documents may come from teaching and research institutions in France or abroad, or from public or private research centers.
L'archive ouverte pluridisciplinaire HAL, est destinée au dépôt et à la diffusion de documents scientifiques de niveau recherche, publiés ou non, émanant des établissements d'enseignement et de recherche français ou étrangers, des laboratoires publics ou privés. 


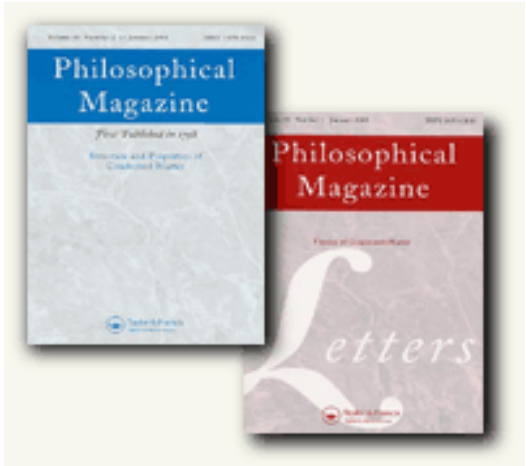

\section{Determination of Plastic Properties of Polycrystalline

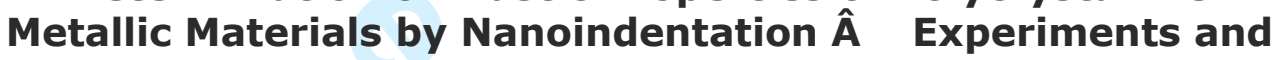 Finite Element Simulations}

\begin{tabular}{|r|l|}
\hline Journal: & Philosophical Magazine \& Philosophical Magazine Letters \\
\hline Manuscript ID: & TPHM-05-Dec-0546.R1 \\
\hline Journal Selection: & Philosophical Magazine \\
\hline Date Submitted by the & 10 -Mar-2006 \\
\hline Complete List of Authors: & $\begin{array}{l}\text { Backes, Bjoern; University Erlangen-Nürnberg, Materials Science \& } \\
\text { Engineering, Institute I } \\
\text { Durst, Karsten; University Erlangen-Nürnberg, Materials Science \& } \\
\text { Engineering, Institute I } \\
\text { Goeken, Mathias; University Erlangen-Nürnberg, Materials Science } \\
\text { \& Engineering, Institute I }\end{array}$ \\
\hline Keywords: & AFM, FEM, nanoindentation, ultrafine-grained metals \\
\hline Keywords (user supplied): & stress-strain-curves, pile-up \\
\hline
\end{tabular}

\section{今) ScholaroNE" \\ Manuscript Central}




\title{
Determination of Plastic Properties of Polycrystalline Metallic Materials by
} Nanoindentation - Experiments and Finite Element Simulations

\author{
B. BACKES, K. DURST, M. GÖKEN \\ Materials Science and Engineering, University Erlangen - Nürnberg D-91058 Erlangen, \\ Germany
}

\begin{abstract}
Nanoindentation experiments at low indentation depths are strongly influenced by micromechanical effects like the indentation size effect, the pile-up or sink-in behaviour and the crystal orientation of the investigated material. For an evaluation of load-displacement data and a reconstruction of stress-strain curves from nanoindentations, these micromechanical effects need to be considered. The influence of size effects on the experiments were estimated by comparing the results of finite element simulation and experiments, using uniaxial stress-strain data of the indented material as input for the simulations. The experiments were performed on conventional und ultrafine-grained copper and brass and the influence of the indentation size effect and the pile-up formation is discussed in terms of microstructure. Applying a pile-up correction on Berkovich and cube-corner indentation data, a piecewise reconstruction of stress-strain curves from load-displacement data is possible with Tabor's concept of representative strain. A good approximation of the slope of the stress-strain curve from the indentation experiments is found for all materials down to an indentation depth of $800 \mathrm{~nm}$.

Keywords: Nanoindentation; Stress-strain-curves; Pile-up, AFM, FEM
\end{abstract}

\section{INTRODUCTION}

The determination of monotonic stress-strain curves from indentation data has been the focus of many studies. Different indenter shapes like spherical, conical and pyramidal indenter geometries have been used for finding a relation between uniaxial deformation behaviour and the deformation resistance of materials under the complex stress field found during indentations $[1,2,3,4]$. Most work is based on Tabors concept on the representative strain, which states, that hardness has a simple linear relation $\left(H=C \sigma_{\mathrm{y}}\right)$ with the flow stress $\sigma_{\mathrm{y}}$ at a representative strain [5]. In the early work of Tabor and Atkins, values of the representative strain were obtained for indentations with conical indenters with different opening angles [6]. According to Tabors theory a representative strain of 0.08 is found for the Berkovich pyramid and 0.22 for the cube-corner pyramid using Eq. 1, whereas $\theta$ is the angle between the undeformed surface and the indenter. In the experiments values of 0.1 and 0.2 were obtained respectively. By using the two indenter geometries, the stress-strain characteristic of a material is tested at two different applied strains (Fig. 1(a)).

$\varepsilon_{\text {rep }}=0.2 \tan \theta$ 
For metals, which deform fully plastically under pyramidal or conical indents a constraint factor $\mathrm{C}$ of $\sim 3$ is found. Depending on the opening angle of the indenter, the constraint factor is nearly constant for materials with a ratio of modulus to flow stress given by $E / \sigma_{\mathrm{y}}>100$ [7].

For applying Tabors approach on experimental nanoindentation data, the local length scale of the indentation problem needs to be considered. At small indentation depth, below $\sim 10 \mu \mathrm{m}$, an increasing hardness with decreasing indentation depth is found, which is referred to as the indentation size effect [8]. Another important point in the analysis is the influence of the deformation behaviour of material around the impression like the pile-up or sink-in, which leads to a wrong hardness determination by the evaluation of the load-displacement curve using the Oliver/Pharr method $[9,10]$. To address these problems, nanoindentation experiments were performed in brass and copper samples using a Berkovich and a cube-corner indenter. The monotonic stress-strain behaviour of the materials was determined by standard tensile/compression tests and used as input parameters for finite element simulations of the indentations. Some preliminary results of this study were given earlier [11]. In the present paper, the formation of pile-up and the influence of the indentation size effect are discussed in more detail.

\section{EXPERIMENTAL AND FINITE ELEMENT SETUP}

In this study conventional grain sized (CG) copper and brass as well as so called ultrafinegrained (UFG) copper and brass with a different amount of prestraining were used. After annealing and recrystallisation, the CG copper and CG brass (CuZn30) samples had a grain size of $\sim 40 \mu \mathrm{m}$. The UFG materials had a grain size of $\sim 0.4 \mu \mathrm{m}$ for copper and $\sim 0.7 \mu \mathrm{m}$ for brass. The UFG materials were produced by equal channel angular pressing (ECAP) $[12,13]$, courtesy of R.Z. Valiev, UFA State Aviation Technical University, Russia.

The macroscopic mechanical properties of the materials were determined by strain controlled tensile and compression tests. For each material, samples prestrained up to a plastic strain of 0.1 and over 0.2 were produced, which were used for indentation experiments. After deformation, the samples were sectioned, grinded and polished with final vibrational-polishing with nanoscale $\mathrm{SiO}_{2}$-suspension, followed by electrolytical polishing.

For indentation testing, the samples were mounted by a cyano acrylate glue (superglue) to avoid heating especially of the UFG materials. Indentations with a Berkovich and cube-corner indenter were performed using the continuous stiffness option of the Nanoindenter XP up to a penetration depth of $3 \mu \mathrm{m}$. The standard Oliver/Pharr procedure as implemented in the MTS testworks software was used to evaluate the continuous stiffness measurements. Tip shape calibration was performed using fused quartz as a reference material and the machine compliance was taken into account. The evaluation of cube-corner indentation was done by following the Oliver/Pharr analysis using a $\beta$-factor of 1.034. However, this factor might be very different for cube-corner indentation. The $\beta$-factor is moreover important in the pile-up correction. Nevertheless due to the lack of better data, the analysis is based on Berkovich data.

During indentation of the UFG samples several thousands grains are deformed, compared to mostly single crystalline region in CG materials. It is therefore expected, that even at low indentation depths, the deformation behaviour of UFG materials is dominated by polycrystalline plasticity whereas the deformation of the CG materials is dominated by single crystal 
deformation behaviour. In single crystals a big influence of the indentation size effect and an orientation dependence of the pile-up around the indentation is expected. UFG materials and nanocrystalline materials exhibit a strain rate sensitivity during indentation testing [14]. There might be some effect of strain rate on the deformation resistance of the UFG materials studied here, but currently the strain rate sensitivity is not taken into account.

For the investigation of the pile-up formation, indentations in samples with a different amount of prestraining (recrystallised or initial state, 0.1 prestraining, 0.2 prestraining) were imaged by Atomic Force Microscopy (AFM).

Finite element simulations of the indentations were performed with the ABAQUS/Standard finite element code (Hibbitt, Karlsson and Sorens, Inc.). Rigid conical tips were simulated with an half opening angle of $70.3^{\circ}$ for the Berkovich and $42.3^{\circ}$ for the cube-corner indenter using a axis-symmetrical 2D model with CAX4 elements and a mesh described in [15]. A friction coefficient of 0.2 was used in all simulations. The material was modelled as elastic and piecewise linear-plastic with a yield strength $\sigma_{\mathrm{y}}$ and a reduced elastic modulus of $E_{\mathrm{r}}=E /\left(1-v^{2}\right)$, where $\mathrm{E}$ is Young's modulus and $v$ is Poisson's ratio of the material. The elastic properties of the materials used in the simulations were taken from literature as $E_{\mathrm{Cu}}=129.8 \mathrm{GPa}, E_{\mathrm{Brass}}=110 \mathrm{GPa}$, and $v_{\mathrm{Cu}, \text { Brass }}=0.343$. Plasticity was modelled by the standard von Mises $\mathrm{J}_{2}$ flow criterion. The yield stress and the hardening behaviour of the materials were approximated by piecewise linear isotropic hardening, using the macroscopic properties determined by the tensile and compression tests. Depending on the shape of the stress strain curve, work hardening was described by up to 8 linear segments per stress strain curve.

\section{RESULTS}

The results of the tensile and compression tests are shown in figure 1(a). The UFG materials show a substantial higher strength compared to the CG materials, due to their smaller grain size and high dislocation density. After ECAP processing, UFG copper has already reached its maximum steady-state stress and no additional work hardening is observed, whereas UFG brass shows a substantial amount of work hardening, comparable to the CG materials. For UFG $\mathrm{Cu}$, a linear elastic ideal plastic material definition was found to be sufficient for describing the material response in the FE analysis. For the CG materials, more than 6 linear segments were necessary for a piecewise approximation of the work hardening behaviour. This approach was used, because conventional power law stress-strain behaviour would not give a satisfactory fit at all stress-strain curves.

Figure1

With the continuous stiffness option of the Nanoindenter XP, the contact stiffness and thus the hardness is measured as a function of the indentation depth. Reliable results are obtained at indentation depths above $200 \mathrm{~nm}$. At lower indentation depths, an increasing scattering in data is found. The CG materials exhibit a strong indentation size effect and the hardness even at an indentation depth above $3 \mu \mathrm{m}$ is not constant. For the UFG state, only a small indentation size effect was found. The hardness is nearly constant at indentation depths larger than $500 \mathrm{~nm}$ (Fig. 1(b)). A detailed analysis of the data according to the Nix-Gao theory of the indentation size 
effect is given in $[16,17]$, where the indentation size effect is modelled considering the size of the plastic zone underneath the indenter. The hardness of the CG materials is much lower than the hardness of the UFG materials and moreover UFG brass shows the highest strength due to the UFG structure and the additional solid solution strengthening of the $\mathrm{Cu}$ matrix with the $\mathrm{Zn}$ atoms. In the case of UFG copper, cube-corner and Berkovich indenter show nearly the same hardness due to the elastic ideal plastic deformation behaviour of the material. Moreover the modulus as determined by Berkovich (i.e. $\mathrm{E}_{\mathrm{UFG} \mathrm{Cu}}=137+-7 \mathrm{GPa}$ ) and cube-corner (i.e. $\mathrm{E}_{\mathrm{Cu}}=$ $131+-3 \mathrm{GPa}$ ) indentation is about the same, even though the same $\beta$-factor was used for analyzing the indentation modulus.

\section{Comparison of computational and experimental results}

Fig. 2 (a) shows a comparison of simulated and experimental load-displacement curves for the UFG materials. The indentations and simulations were performed using a Berkovich and a cube-corner indenter. Due to the smaller opening angle of the cube-corner indenter, a much higher indentation depth is reached at the same maximum applied load. The simulated loaddisplacement-curves are in very good agreement with the experimental curves for the UFG materials, down to a maximum indentation depth of about $500 \mathrm{~nm}$ for both indenter geometries. Using the simulated plastic zone sizes, we calculate that at a maximum indentation depth of $3 \mu \mathrm{m}$, up to 600000 grains are deformed plastically depending on the grain size and the used indenter, whereas in the CG materials, the indentations are performed mostly in a single grain. The simulated and measured load-displacement curves for the CG materials in the initial (recrystallised state) condition and after $20 \%$ prestraining are shown in figure 2(b). As expected, a much higher indentation load is reached in the prestrained material at the same maximum depth. In the unstrained material a bigger deviation between simulated and experimental data is found for both $\mathrm{CG}$ copper and $\mathrm{CG}$ brass. The indentation size effect results in a higher strength of the material at small depths, which is not considered in the simulations (see figure 1(b)). After prestraining of the materials, simulations and experimental data agree nearly as well as in the case of the UFG materials. Due to the higher dislocation density and the microstructure evolution during the deformation, the influence of the indentation size effect decreases and leads to the good agreement of the experimental and simulated load-displacement curves. The data clearly indicates that after prestraining, the indentation response of the $\mathrm{CG}$ material at a maximum indentation depth of $\sim 3 \mu \mathrm{m}$ corresponds to the macroscopic deformation behaviour of the materials.

figure 2

\section{$\underline{\text { Pile-up correction }}$}

The simulated load-displacement curves were evaluated using the Oliver/Pharr method. The contact stiffness was determined with linear fitting of $10 \%$ of the unloading curve in the case of the simulations. The experimental data were evaluated averaging the continuous hardness data between 2800 and $2950 \mathrm{~nm}$. The experimentally determined and simulated Oliver/Pharr hardness of the UFG materials are in good agreement, as has already been shown by comparing of the load-displacement curves. Using the real contact area from the finite element simulations to determine the true finite element hardness, we find that the true hardness is much smaller than the conventional Oliver/Pharr hardness. This is related to piling up of the material around the 
indenter, which increases, as can be imaged by atomic force microscopy, with the amount of prestraining applied to the material (Fig. 3).

Figure 3

In the initial $\mathrm{CG}$ state of $\mathrm{Cu}$ only a very small pile-up formation is found. Naturally in nanoindentations on coarse grained materials, indentations are performed within single grains, which correspond basically to a single crystal. In single crystals the pile-up formation depends strongly on the orientation of the crystal and the work hardening. Pile-up is manly formed by cross slip of dislocations. The pile-up height and distribution depends thus on the orientation of slip systems relative to the surface [18]. An the other hand, due to the initially low dislocation density and the high work hardening rates, the material will show far field plasticity. Material close to the indenting tip will strongly strain harden and displace soft surrounding material. Therefore, depending on the orientation of the indented grain, no or only small pile-up formation is observed for the annealed $\mathrm{Cu}$ material. A more detailed discussion on the pile-up formation in single crystals can be found in $[18,19,20]$

Work hardening of copper by prestraining it up to 0.1 plastic strain, leads to the formation of pile-up around the indent (Fig. 1(b)). There is still a significant anisotropy of the pile-up after prestraining the material. After ECAP processing of the material, copper has an UFG microstructure and shows nearly isotropic pile-up formation around the indentation, owing to high number of deformed grains and the very high dislocation density. For a quantification of the pile-up formation, the normalised pile-up height is calculated as the ratio of the maximum pileup height to residual indentation depth, as determined by AFM. A normalised pile-up height of $\sim 0.077$ was found for a (110) oriented $\mathrm{Cu}$ single crystal. For the annealed $\mathrm{Cu}$ the normalised pileup height was about $\sim 0.025$, whereas after prestraining up to 0.25 plastic strain, a normalised pile-up height of $\sim 0.25$ was found. For the UFG state, with nearly homogeneous pile-up formation, the normalised pile-up height was around $\sim 0.19$.

For quantifying the hardness of the material, a pile-up correction as proposed by Joslin and Oliver was used on the indentation data. The approach is based on the analysis of the contact area using Sneddons equation, assuming a constant and depth independent modulus of elasticity [21]. Under these assumptions, the contact area $A$ is directly calculated from the load $F$ and the contact stiffness $S$ :

$$
A=\frac{\pi}{4} \frac{S^{2}}{\beta^{2} E_{r}{ }^{2}} \Rightarrow H_{P U}=\frac{4}{\pi} \beta^{2} E_{r}^{2} \frac{F}{S^{2}}
$$

A correction factor $\beta$ of 1.034 was used to correct for the pyramidal shape of the indenter in the Sneddon equation. This might be not the appropriate factor for cube-corner geometry. The experimental pile-up correction does not work reliably for all of our experimental data, specifically for materials where no piling-up occurs even higher hardness values can be found. The exact reason for that is not yet clear, but due to the quadratic dependence of the contact stiffness, the pile-up corrected hardness is very sensitive to this input parameter. For the UFG materials, which show a significant amount of pile-up around the indentation, this approach works quite good. Figure 4 shows the pile-up correction applied to the hardness measurements on UFG brass in comparison with the finite element hardness. The experimental and simulated Oliver/Pharr hardness agree very well, as has been already indicated by the load-displacement 
curves. Moreover, the true finite element hardness using the true contact area and the pile-up corrected hardness yield about the same values. Only for the material with a prestraining of 0.25 the data does not agree, which is related to the fact, that after 0.25 straining, ideal plastic material behaviour was assumed in the simulations, which is most probably not the case.

\section{Determination of stress-strain properties from nanoindentation data}

For the determination of stress-strain curves, Tabors concept and the pile-up correction need to be applied to the experimentally determined hardness data for Berkovich and cube-corner indentations. First, the constraint factor was determined using the hardness and stress-strain data on UFG copper, as calculated by the FE analysis. UFG copper deforms in a steady state condition and does not show any additional hardening during indentation or during uniaxial deformation. The hardness for indentations with Berkovich and cube-corner tips is moreover nearly the same. A constraint factor of 2.85 was found for both Berkovich and cube-corner indenter from the simulations, using the true finite element hardness. With the constraint factor of 2.85 , the representative strain is determined by comparing the uniaxial stress-strain data with the simulated hardness values. A representative strain for Berkovich of 0.1 and for cube-corner of 0.2 was found to approximately yield an indentation hardness given by $H=2.85 \sigma_{\mathrm{y}}\left(\varepsilon_{\mathrm{rep}}\right)$ for all materials. Using these data, the experimental hardness measurements are evaluated. Figure 5(a) and 5(b) show the stress-strain curves for $\mathrm{CG}$ and UFG brass and copper with the representative Berkovich stress as $H_{\mathrm{B}} / 2.85$ at a representative strain of $\varepsilon_{\mathrm{B}}=0.1$, as well as the representative cube-corner stress as $H_{\mathrm{C}} / 2.85$ at a representative strain of $\varepsilon_{\mathrm{cc}}=0.2$. The hardness data of Berkovich and cube-corner indenter were evaluated for the same contact area and thus at a different penetration depth. The Oliver/Pharr data yield a higher stress level for all materials. Applying the pile-up correction as discussed above, a very good prediction of the UFG material stress-strain curve can be obtained, while that of CG material reaches a much higher stress level due to the indentation size effect. In the case of CG copper no pile-up correction was applied owing to the very small pile-up formation for the initial state as is shown in figure 3 . The work hardening coefficient as given by the slope between Berkovich and cube-corner hardness is in a good agreement with the compression data for both UFG and CG materials. Extrapolating these data linearly to zero strain leads to a yield stress which is about $11 \%$ to high for the UFGmaterials, while for the CG materials, this linear intercept is of only little relevance.

Figure 5

\section{CONCLUSIONS}

A piecewise reconstruction of stress-strain curves from load-displacement curves was carried out using Tabor's concept on representative strain. From the uniaxial stress-strain response of the material and finite element simulations of the indentation process, effects like piling-up of material around the indentation and the indentation size effect were considered. The experiments as well as the simulations were conducted using cube-corner and Berkovich indenter. We find an excellent agreement between simulations and experiments for the UFG materials from which a representative strain of $\varepsilon_{\mathrm{B}} \approx 0.1$ and $\varepsilon_{\mathrm{cc}} \approx 0.2$ was determined. Moreover, the AFM observations of the indentations confirmed, that the pile-up clearly depends on the work hardening behaviour of the material. The annealed $\mathrm{Cu}$ crystal showed nearly no pile-up around the indentation, 
whereas after 0.1 plastic pre-straining, the material exhibited pile-up. In the annealed condition, a significant influence of the indentation size effect on the materials response is found, whereas after prestraining, the influence of the ISE is greatly reduced. The UFG materials show a very distinct pile-up behaviour, where the pile-up is made of many individual grains. It is found, that the indentation response of UFG materials can be described by conventional J2 flow theory down to indentation depths of about $800 \mathrm{~nm}$. Furthermore, a correction of the influence of pile-up on the determination of contact area was possible for the UFG materials. With Berkovich and cubecorner indentation, Tabors concept and the pile-up correction, a determination of stress-strain curves from indentation data was possible for the UFG materials. For the conventional material too high stress levels were determined, which is due to the influence of the indentation size effect.

\section{ACKNOWLEDGEMENT}

The support of UFG materials by R.Z. Valiev and H.W. Höppel is gratefully acknowledged. 


\section{REFERENCES}

[1] B. Taljat, T. Zacharia, F. Kosel, Int. J. Solids Structures, 354411 (1998)

[2] A. DiCarlo, H. T. Y. Yang, S. Chandrasekar, J. Mat. Res., 182068 (2003)

[3] M. Dao, N. Chollacoop, et al., Acta mater., 493899 (2001)

[4] Y.-T. Cheng, C.-M. Cheng, Phil. Mag. Let., 77, 39 (1998)

[5] D. Tabor, The hardness of metals, Oxford University Press (1950).

[6] A.G. Atkins, D. Tabor, J. Mech. Phys. Solids 13149 (1965).

[7] Y. Cheng, C. Cheng, Surf. Coat. Technol. 133417 (2000).

[8] W.D. Nix, H. Gao, J. Mech. Phys. Solids 46441 (1998).

[9] W.C. Oliver, G.M. Pharr, J. Mater. Res. 71564 (1992).

[10] A. Bolshakov, G.M. Pharr, J. Mater. Res. 131049 (1998).

[11] K. Durst, B. Backes, M. Göken, Mater. Res. Soc. Symp. Proc., 841 R11.4.1 (2005)

[12] V. M. Segal, Patent of UdSSR, No. 575892, (1977)

[13] R. Z. Valiev, A. V. Korznikov, R. R. Mulyukov, Mater. Sci. Eng. A168 141 (1993)

[14] J. Mueller, K. Durst, D. Amberger, M. Göken, Materials Science Forum, 31503 (2006)

[15] K. Durst, M. Göken, H. Vehoff, J. Mater. Res. 1985 (2004)

[16] K. Durst, B. Backes, M. Göken, Scripta Mat. 521093 (2005)

[17] K. Durst, B. Backes, O. Franke M. Göken, accepted for pub. Acta Mat. (2006)

[18] R. Smith, D. Christopher, S. D. Kennz, et al., Physical Review B, 67245405 (2003)

[19] D. Christopher, R. Smith, A. Richter, Nanotechnology, 12372 (2001)

[20] Y. Wang, D. Raabe, C. Klüber, F. Roters, Acta Mat., 522229 (2004)

[21] D.L. Joslin, W.C. Oliver, J. Mater. Res. 5123 (1990). 


\section{Figure captions}

Figure 1. Mechanical properties of UFG brass, UFG copper, CG brass and CG copper (a) True stress - inelastic strain curves, strain rate $5^{*} 10^{-4}$. Shown is schematically tThe representative strain for Berkovich and cube-corner indenter is indicate (b) Depth dependent hardness.

Figure 2. Experimentally determined load-displacement curves and simulated load-displacement curves for indentations performed with Berkovich and cube-corner indenter. (a) UFG brass and (b) CG brass with cube-corner indenter.

Figure 3. Pile-up formation around indentation after different amount of prestraining of the material (a) CG copper initial state, (b) CG copper 10\% prestraint and (c) UFG copper.

Figure 4. Correction of pile-up. Shown is the Oliver-Pharr hardness and the pile-up corrected hardness using Sneddon equation for the experimental data and the corresponding simulated hardness using Oliver /Pharr contact area and true finite element contact area.

Figure 5. Reconstruction of stress-strain curves using Tabors approach on experimentally determined hardness. (a) Copper (b) Brass. Note that pile-up correction works relatively well for the UFG materials and moreover, nearly no influence of the indentation size effect is found. The stress in the CG materials is at this indentation depth much higher than on a macroscopic length scale. 

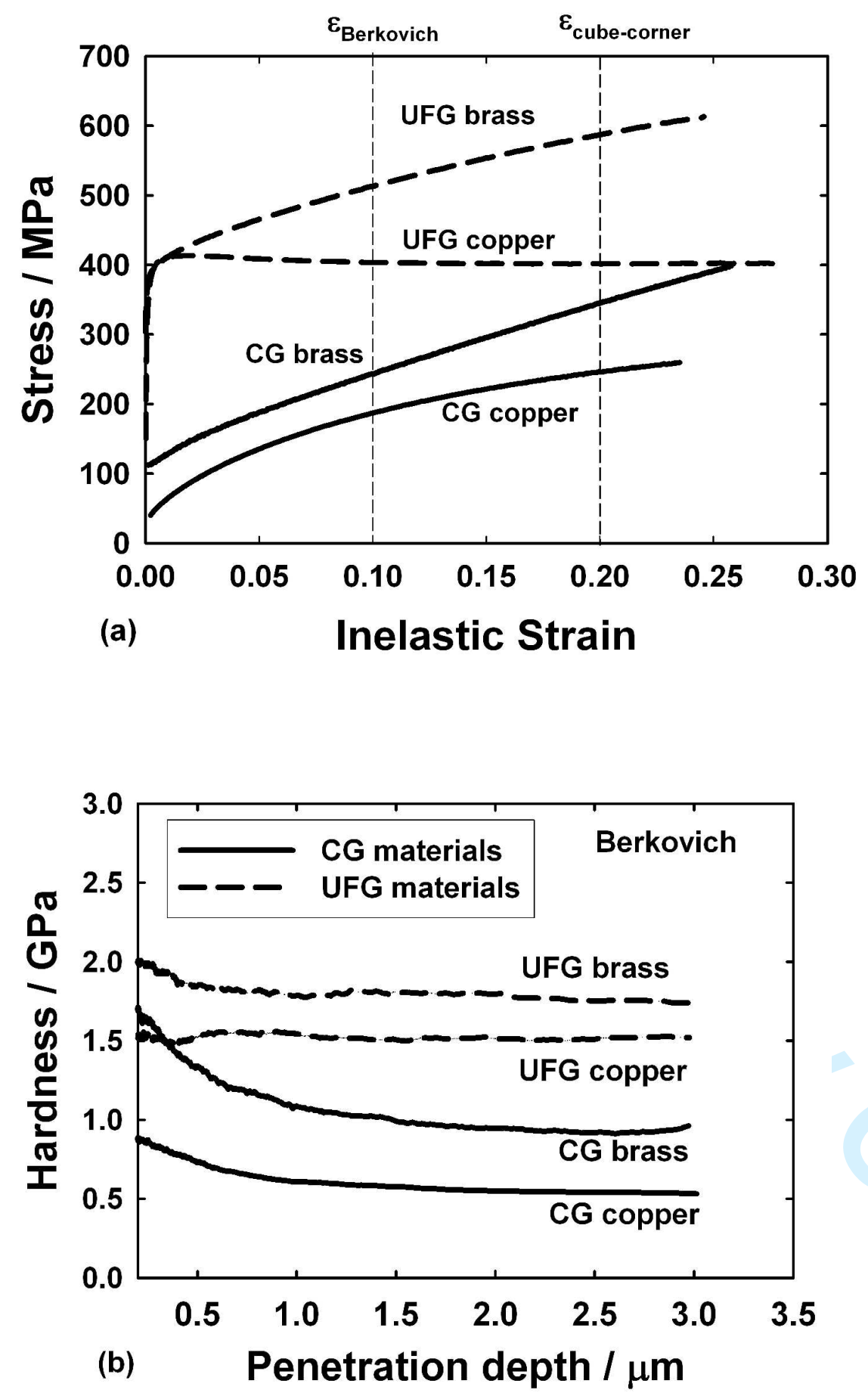

Figure 1. 


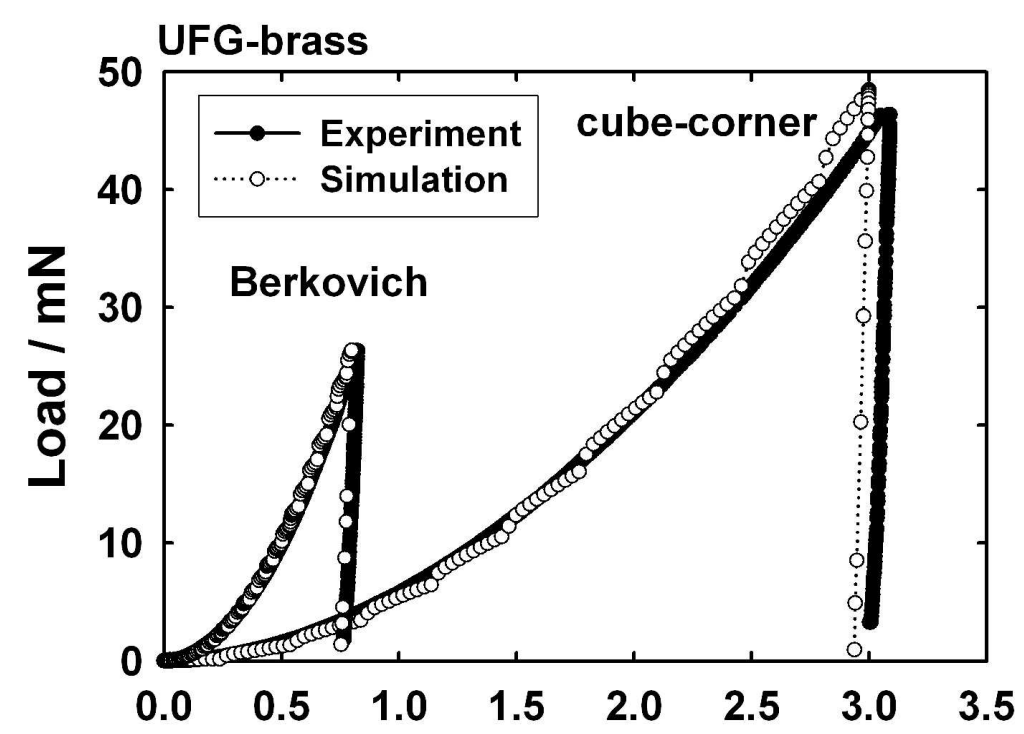
(a)
Displacement / $\mu \mathrm{m}$

CG brass

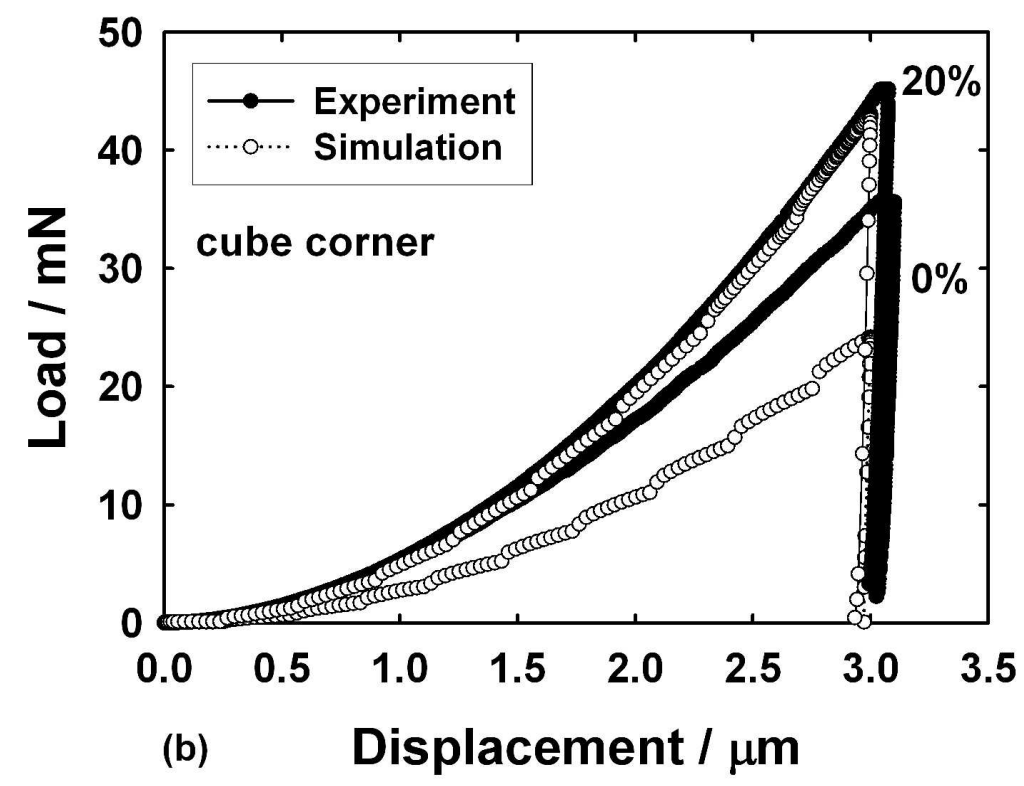

Figure 2. 


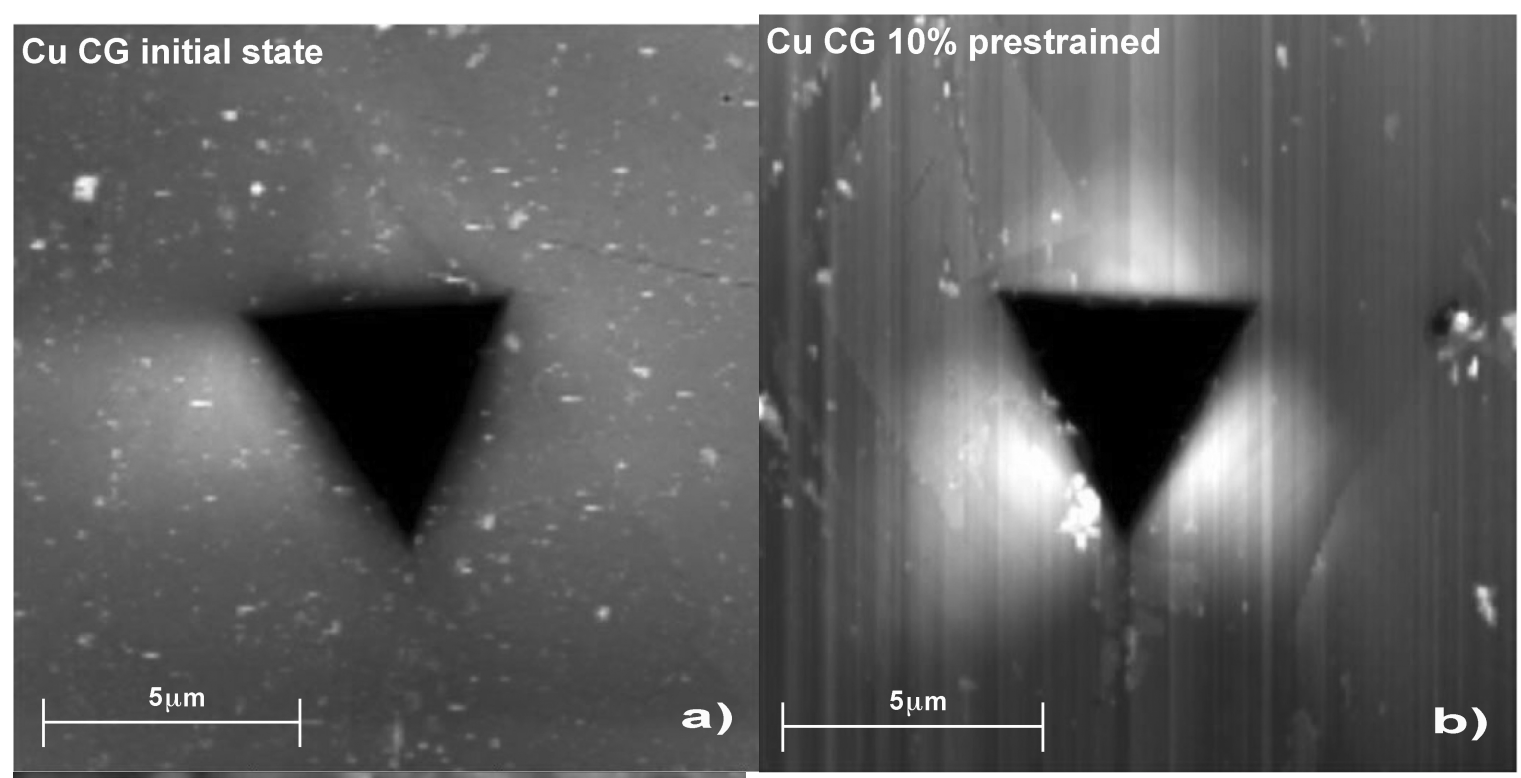

\section{Cu UFG initial state}

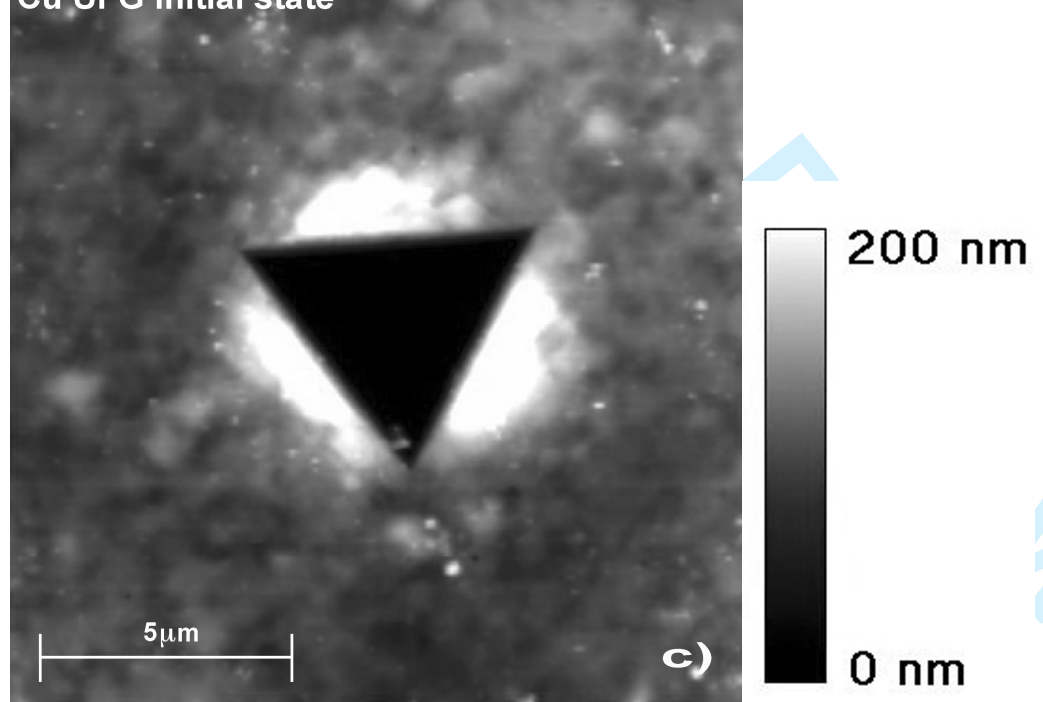

Figure 3. 


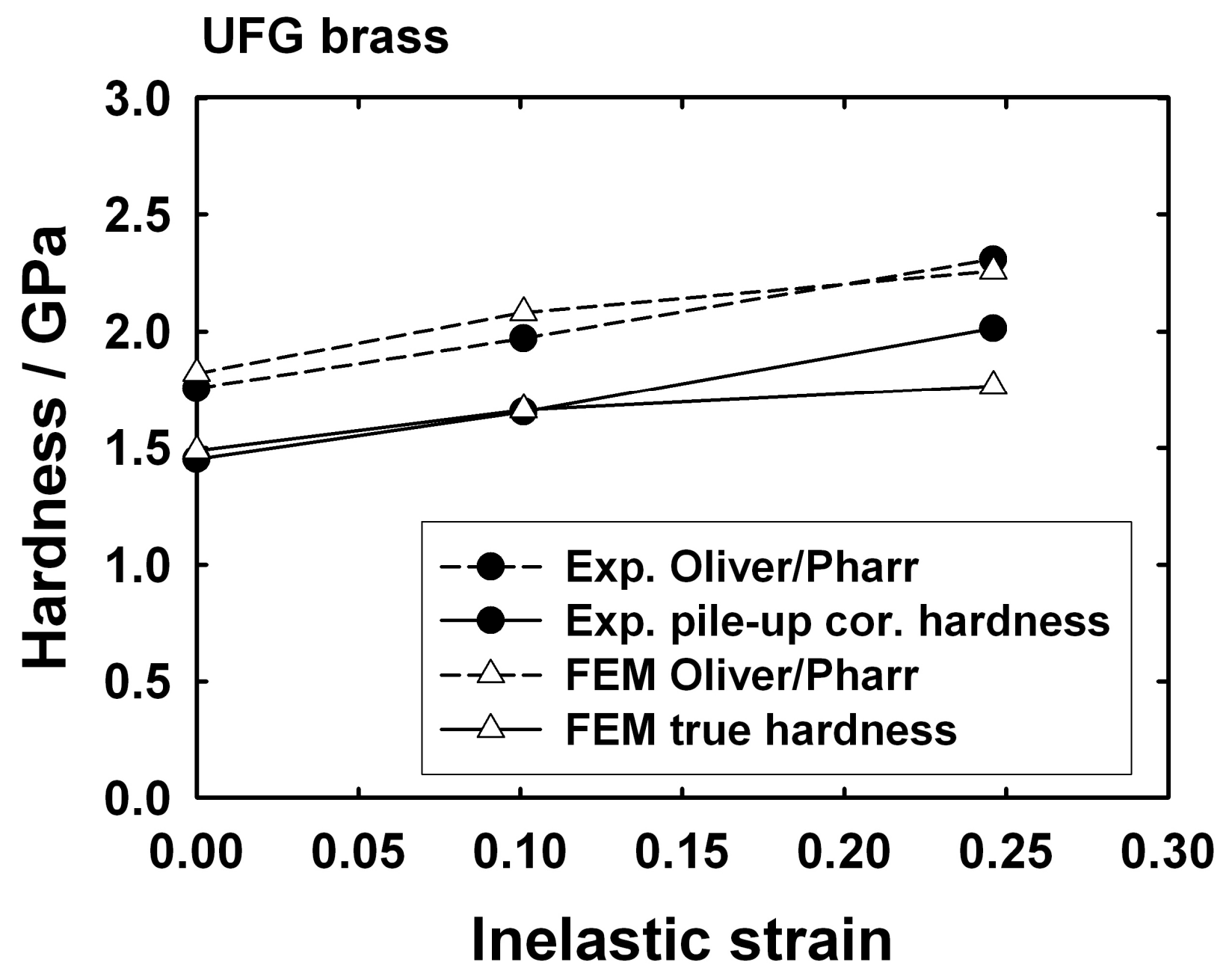

Figure 4. 

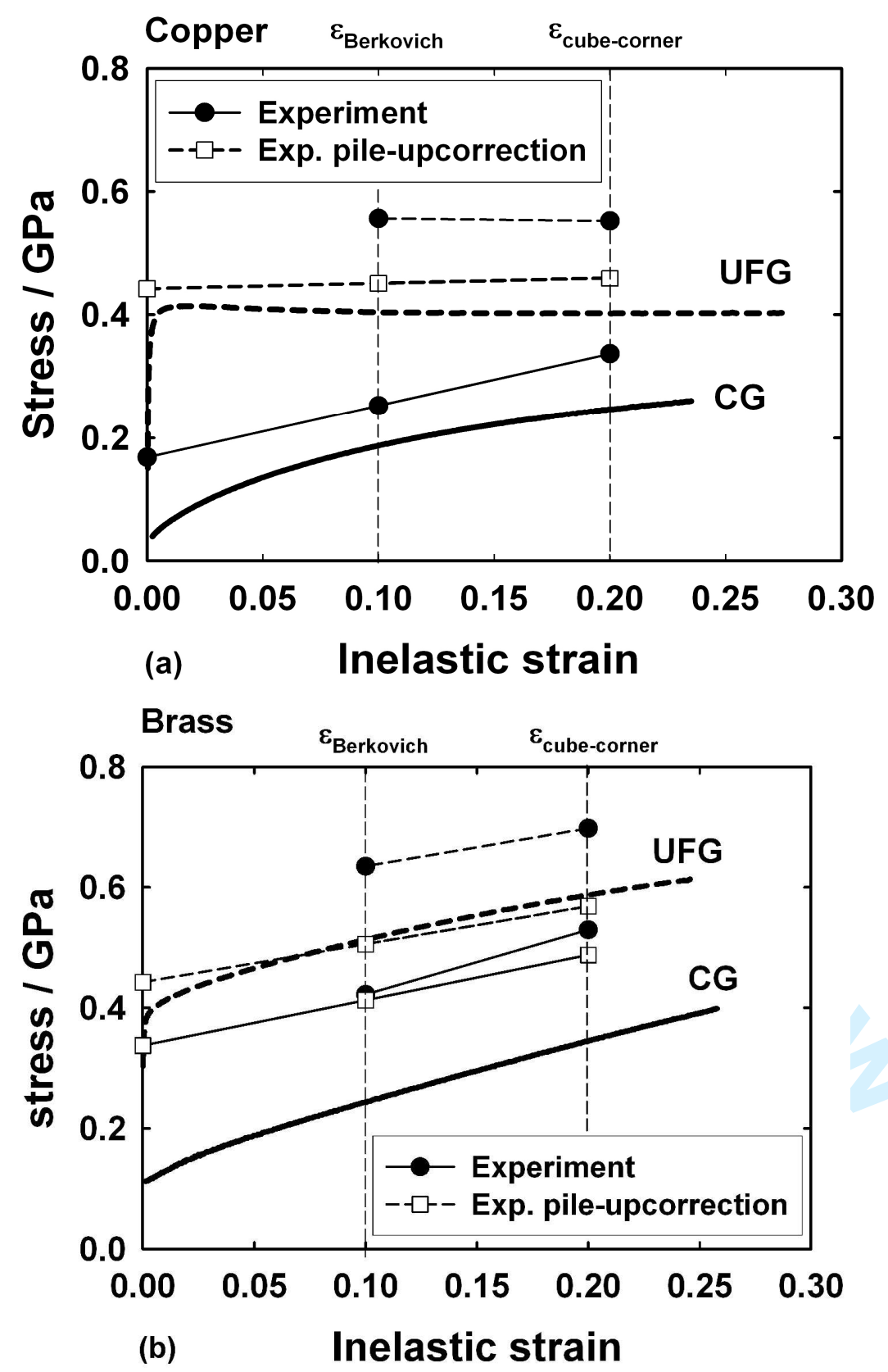

Figure 5 